\title{
Metabolic Perspectives for Non-classical Congenital Adrenal Hyperplasia With Relation to the Classical Form of the Disease
}

\author{
Djuro Macut ${ }^{1 *}$, Vera Zdravković ${ }^{2}$, Jelica Bjekić-Macut ${ }^{3}$, George Mastorakos ${ }^{4}$ and \\ Duarte Pignatelli ${ }^{5}$
}

\begin{abstract}
${ }^{1}$ Clinic of Endocrinology, Diabetes and Metabolic Diseases, Clinical Center of Serbia, Faculty of Medicine, University of Belgrade, Belgrade, Serbia, ${ }^{2}$ Division of Endocrinology, University Children's Hospital, Faculty of Medicine, University of Belgrade, Belgrade, Serbia, ${ }^{3}$ Department of Endocrinology, UMC Bežanijska kosa, Faculty of Medicine, University of Belgrade, Belgrade, Serbia, ${ }^{4}$ Unit of Endocrine Diseases, Aretaieion Hospital, National and Kapodistrian University of Athens, Athens, Greece, ${ }^{5}$ Faculty of Medicine, Instituto de Patologia e Imunologia Molecular da Universidade do Porto/I3S Research Institute, Hospital S João, University of Porto, Porto, Portugal
\end{abstract}

OPEN ACCESS

Edited by:

Richard Ivell,

University of Nottingham,

United Kingdom

Reviewed by:

Dana Manuela Savulescu, National Institute of Communicable

Diseases (NICD), South Africa

Ariadni Spyroglou,

University Hospital Zürich, Switzerland

${ }^{*}$ Correspondence:

Djuro Macut

djmacut@gmail.com

Specialty section:

This article was submitted to

Reproduction,

a section of the journal

Frontiers in Endocrinology

Received: 31 October 2018 Accepted: 19 September 2019

Published: 02 October 2019

Citation:

Macut $D$, Zdravković $V$,

Bjekić-Macut J, Mastorakos G and

Pignatelli D (2019) Metabolic

Perspectives for Non-classical Congenital Adrenal Hyperplasia With Relation to the Classical Form of the Disease. Front. Endocrinol. 10:681. doi: 10.3389/fendo.2019.00681
Non-classical congenital adrenal hyperplasia (NC-CAH) represents mild form of CAH with the prevalence of 0. 6 to $9 \%$ in women with androgen excess. Clinical and hormonal findings in females with $\mathrm{NC}-\mathrm{CAH}$ are overlapping with other hyperandrogenic entities such as polycystic ovary syndrome hence causing difficulties in diagnostic approach. Metabolic consequences in subjects with $\mathrm{NC}-\mathrm{CAH}$ are relatively unknown. We are lacking longitudinal follow of these patients regarding natural course of the disease or the therapeutic effects of the different drug regiments. Patients with NC-CAH similarly to those with classical form are characterized with deteriorated cardiovascular risk factors that are probably translated into cardiometabolic diseases and events. An increased preponderance of obesity and insulin resistance in patients with NC-CAH begin at young age could result in increased rates of metabolic sequelae and cardiovascular disease later during adulthood in both sexes. On the other hand, growth disorder was not proven in patients with $\mathrm{NC}-\mathrm{CAH}$ in comparison to $\mathrm{CAH}$ patients of both gender characterized with reduced final adult height. Similarly, decreased bone mineral density and osteoporosis are not constant findings in patients with NC-CAH and could depend on the sex, and type or dose of corticosteroids applied. It could be concluded that NC-CAH represent a particular form of $\mathrm{CAH}$ that is characterized with specificities in clinical presentation, diagnosis, therapeutic approach and metabolic outcomes.

Keywords: non-classical congenital adrenal hyperplasia, metabolism, obesity, cardiovascular risk, stature, osteoporosis, glucocorticoids, antiandrogens

\section{INTRODUCTION}

The non-classical form of congenital adrenal hyperplasia (NC-CAH) was initially called late-onset as clinical presentation was observed in adolescents and adults. Presentation of NC-CAH is subtle and diagnosis requires implementation of different tests to exclude other problems. Moreover, clinical expression of NC-CAH is variable in patients carrying the same mutation. This suggests that additional factors may modify the clinical expression of the disease including age, steroid metabolic 
pathways, variation in androgen production, individual sensitivity to androgens, differences in skin sensitivity to androgens and possibly the existence of other genes modifying 21-hydroxylase activity $(1,2)$. In patients with $\mathrm{NC}-\mathrm{CAH}$ predominant signs are those of androgen excess including premature pubarche, acne, hirsutism, polycystic ovary syndrome (PCOS) and subfertility (3).

$\mathrm{NC}-\mathrm{CAH}$ is more frequently observed in females. The preponderance of $\mathrm{NC}-\mathrm{CAH}$ in women with androgen excess, and according to ethnicity and genotype, is ranging from 0.6 to $9 \%$ (2). Males with $\mathrm{NC}-\mathrm{CAH}$ are diagnosed significantly less often than females due to less frequently presented and recognizedsigns of androgen excess (4). One of the scarce and small studies showed in men with NC-CAH premature pubarche in $29 \%$ before 9 years of age (5). Gynecomastia has been reported as the presenting symptom in two male adolescents with nonclassical congenital adrenal hyperplasia. Considering diagnosing $\mathrm{NC}-\mathrm{CAH}$, basal values of 17-OHP below $6 \mathrm{nmol} / \mathrm{L}$ were found in $2.1 \%$ of subjects with disease while concentrations of over 30 $\mathrm{nmol} / \mathrm{L}$ after ACTH test is confirmatory for diagnosis (5).

As $\mathrm{CAH}$ is considered as disease spectrum, disease phenotype is ascertained by the less severe mutation with the highest residual enzymatic activity of CYP21A2 (6). The prevalence of classical CAH is from $1: 10,000$ to $1: 20,000$ births $(7,8)$ while in the nonclassical CAH it is 1:1,000 births (9) and occurs in about $6 \%$ of hirsute women (10) (Supplementary Table 1).

Metabolic consequences in subjects with $\mathrm{NC}-\mathrm{CAH}$ are relatively unknown and we are missing longitudinal follow up data of these patients regarding either the natural course of the disease or the outcomes of therapeutic regiments mainly based on glucocorticoids. Therefore, metabolic consequences in NC-CAH subjects could be analyzed from scarce clinical studies (11) or extrapolated from as well scarce clinical follow-up of patients with classical CAH.

\section{CLINICAL CHARACTERISTICS IN DIFFERENT AGE PERIODS}

\section{Growth Differences}

\section{Patients With Non-classical CAH}

Both boys and girls with NC-CAH could be characterized with fast linear growth, advanced bone age with consequent tall stature $(4,12)$. On the other hand, short stature was reported in subjects with NC-CAH as well particularly in patients on glucocorticoid therapy that commenced before the start of puberty. However, risk for short stature is relatively small with majority of children having almost normal final height (13).

\section{Patients With Classical CAH}

Birth length of salt wasting (SW) boys and girls at neonatal screening is above the average at birth while during infancy their height velocity declines by the age of 1.5 years in boys, and by the age of 3 years in girls (14). Patients with simple virilizing (SV) form of $\mathrm{CAH}$ have relative androgen insensitivity during the first year of life with consequent absence of increased height velocity (15). Before puberty, patients with SW are growing close to the reference values. True pubertal growth spurt is not noticeable in both forms and genders (16).

The first meta-analysis on the height outcome in classical $\mathrm{CAH}$ showed similar mean final height SD score (SDS) of $-1.37(\sim 10 \mathrm{~cm})$ in both genders compared to their target height (17). Studies on the outcomes in adults with classical $\mathrm{CAH}$ showed those on smaller glucocorticoid doses had slightly better SDS outcome of -1 below the target height. Patients with both CAH forms had reduced final adult height. However, women with simple virilizing form of $\mathrm{CAH}$ had shorter stature in comparison to those with salt wasting phenotype (18) (Supplementary Table 1).

\section{Sexual Maturation Characteristics}

Howig et al. reported that the mean age for the onset of puberty was 9.8 years for girls with simple virilizing form, and 10.3 years for girls with SW CAH, and similar age at menarche of 13.3 and 13.7 years, respectively. In boys with SV form the onset of puberty was at 9.8, and 10.6 years for those with SW (19). Moreover, dissociation of pubarche and adrenarche was shown in classical CAH. Namely, in both boys and girls an earlier pubarche, gonadarche, and thelarche was confirmed with the absence of typical signs of adrenarche. Children having advanced skeletal maturation are at risk for early pubertal development (20). Elevated androgens may induce secondary central precocious puberty. High adrenal androgens resulting from non-suppression of HPA axis cause early puberty in both forms, more prevalent in SV than SW forms (21).

In those with NC-CAH pubertal delay, pubertal development progressed well after the initiation of glucocorticoid therapy with attainment of menarche and subsequently regular menstrual cycles (22) (Supplementary Table 1).

\section{IMPORTANCE OF DIFFERENTIAL DIAGNOSIS}

\section{NC-CAH and Early Adrenarche/Pubarche}

Adrenarche is characterized with elevated secretion of adrenal androgen precursors (AAPs), namely, dehydroepiandrosterone (DHEA) and DHEA-sulfate (DHEAS) that occurs at 5-8 years of age (23). Premature adrenarche (PA) and premature pubarche (PP) are defined as early appearance (before 9 years in boys and 8 years in girls) of axillary and pubic hair, adult type body odor or acne, with the absence of true central puberty. AAPs concentrations are above the prepubertal level with DHEAS $>1 \mu \mathrm{mol} / \mathrm{l}$ (termed as biochemical adrenarche) (24). The mechanisms of PA are not fully elucidated but the obesity and genetic factors seems to contribute in apparently multifactorial etiology (24).

Premature adrenarche is a benign condition but before the diagnosis can be accepted, differential diagnosis should consider defects of cortisol synthesis, androgen-producing tumors originated from adrenals or gonads, central precocious puberty, primary hypothyroidism, Cushing's syndrome, exposure to exogenous androgens, and most importantly NC-CAH (25).

The reported prevalence of $\mathrm{CAH}$ in $\mathrm{PP}$ patients differs from study populations ( $0-43 \%$ for all types of CAH) (26). 
Differential diagnosis between PA and NC-CAH, as well as other genetic reasons for adrenal hyperandrogenism, is not always obvious based on clinical examination. However, rapidly accelerating growth, remarkable androgenic signs and bone age advancement, and a positive family history are clues toward a genetic disorder (27).

\section{NC-CAH and PCOS}

Clinical and hormonal findings that are overlapping with other hyperandrogenic entities such as PCOS may cause some difficulties in diagnostic approach in patient with suspected NC$\mathrm{CAH}$. Therefore, one should question what endocrine tests are appropriate to confirm or exclude $\mathrm{NC}-\mathrm{CAH}$, and if genetic analyses are indicated $(5,28,29)$.

PCOS is considered frequent endocrine disease of women during reproductive period that is characterized with hyperandrogenism (30). As PCOS is a disease of exclusion, clinicians are obliged to perform necessary basal and functional endocrine testing to exclude other causes of androgen excess. Serum total testosterone determination is the main androgen determinant of PCOS (30). Approach to the hormonal analyses depends on the severity of hyperandrogenism. Determination of total testosterone is requested in patients with regular menstrual cycles and mild hirsutism (30). Determination of total testosterone together with $\mathrm{FSH}$ and $\mathrm{LH}$ is requested in patients with moderate hirsutism. In subjects with sudden development of hirsutism in adolescents and adults, and high concentrations of testosterone and androstenedione, an additional ACTH stimulation test with determination of 17-OHP together with CYP21A2 genotyping is requested (31).

Gonads could contribute to increase in 17-OHP as they also secrete this hormone. A hyperresponsiveness of 17-OHP to gonadotropin-releasing hormone agonist ( $\mathrm{GnRHa}$ ) is confirming ovarian hyperandrogenism. Hence, PCOS is considered as a result of ovarian thecal cell overactivity associated with 17,20-lyase activity down-regulation (32). As a consequence, hyperandrogenemia in PCOS could lead toward estrogen oversecretion. However, $\mathrm{LH}$ to estradiol ratio is kept normal in functional ovarian hyperandrogenism in the presence of elevated 17-OHP (33).

\section{THERAPEUTIC APPROACH}

\section{Therapy for NC-CAH}

Concerning therapy for NC-CAH patients in contrast to classical $\mathrm{CAH}$ patients, adrenal replacement is not required. Therefore, pharmacological treatment is focused on the management of the signs of androgen excess. Use of glucocorticosteroid (GCS) therapy should be reserved for special outcomes such as restauration of fertility. When talking on the long-term outcomes of androgen excess including menstrual cycle derangement, first line options are antiandrogens and oral contraceptives (34) (Supplementary Table 1).

\section{Therapy for Classical CAH}

\section{Glucocorticoids and All Forms of $\mathrm{CAH}$}

Longitudinal growth and bone age development are the most important clinical parameters for monitoring adequate glucocorticoid replacement in children with CAH (35). Serum levels of 17-OHP, androstenedione and testosterone need to be monitored frequently and the hydrocortisone dose adjusted to maintain treatment efficacy. The levels of androstenedione and testosterone are more important in monitoring the glucocorticoid dosage than 17-OHP that should be kept a little above the normal range.

Analysis of growth in CAH patients reveal that the two most rapid phases of growth (first year of life and pubertal growth spurt) are vulnerable ones, during which glucocorticoid overtreatment should be avoided $(14,19)$. During infancy hydrocortisone dose should be decreased in patients with slower growth velocity, but strict hydrocortisone dose adjustments are necessary during childhood to avoid accelerated growth and advanced skeletal maturation (16). Pharmacokinetics of free cortisol showed shorter half-life in pubertal girls than in pubertal boys (36). Consequently, female patients at puberty need more frequent hydrocortisone replacement regimen. Besides decreased compliance of adolescents with $\mathrm{CAH}$, use of oral contraceptive pills, aromatase inhibitors, thyroxine, or ingestion of hydrocortisone with food could influence cortisol dynamics and altering hydrocortisone dosing (37).

Hydrocortisone three times per day is the mostly prescribed regimen by pediatricians (38). Prednisolone or dexamethasone could be used in children with late puberty and in adults, but are avoided in childhood due to the potent effect on growth. It was observed several rises in cortisol concentrations during the day in children on hydrocortisone therapy. These phased are interchanged with periods of hypocortisolemia between the doses, especially during the night. Reduction of glucocorticoid dose during puberty is of clinical importance as pubertal height gain represent a predictor of final height. On the other hand, low glucocorticoid dose with concomitant hyperandrogenism can lead to premature epiphyseal closure and short stature (17). Other treatment options to improve final height and metabolic outcome might include subcutaneous hydrocortisone infusion through a pump, as well as plenadren (modifiedrelease hydrocortisone) and chronocort (modified-release hydrocortisone formula, under development) that have a delayed and sustained absorption profile (38) (Supplementary Table 1).

\section{Mineralocorticoids}

Endocrine Society (USA) recommended fludrocortisone (0.05$0.2 \mathrm{mg}$ once or twice per day) to be used in all patients with classical CAH (13). Fludrocortisone is used more frequently and in higher doses in patients with more severe genotypes. Overtreatment, defined by renin concentrations either in the lower reference range or suppressed, was only rarely observed throughout the different mutation groups (22) (Supplementary Table 1).

\section{METABOLIC OUTCOMES OF NC-CAH}

\section{Obesity and Cardiometabolic Risk During Life}

\section{Non-classical CAH}

One third of untreated NC-CAH women have insulin resistance $(11,39)$. In children with both classical CAH and NC-CAH 
prevalence of obesity is approximately $35 \%$ and exceeds obesity rates in children and adolescent in the general population (18). Obese children with either forms of $\mathrm{CAH}$ are hyperinsulinemic and hyperleptinemic but predominantly in those with classical form of CAH $(18,40)$. However, Saygili et al. did not show difference in leptin concentrations in hyperinsulinemic and hyperandrogenemic adult women with $\mathrm{NC}-\mathrm{CAH}$ in comparison to controls (39). Moreover, an association of leptin levels with hyperinsulinemia and hyperandrogenism in women with NC$\mathrm{CAH}$ was not established with conclusion that potential relation of leptin with hyperinsulinemia and reproduction in $\mathrm{NC}-\mathrm{CAH}$ patients need further investigation (39).

We are lacking clinical studies in NC-CAH children regarding obesity, metabolic syndrome and their consequences (41). Concerning adult NC-CAH patients, it was recently shown an increased risk of metabolic and cardiovascular morbidities in both males and females (42).

Adrenal androgen secretion is increased in $\mathrm{NC}-\mathrm{CAH}$ in the presence of normal levels of ACTH in the majority of subjects (43). Moreover, NC-CAH patients have normal levels of DHEAS while androstenedione and testosterone are similarly elevated to the levels in PCOS women $(43,44)$. As mentioned previously, altered enzyme kinetics due to CYP21A2 missense mutations is associated with adrenal androgen oversecretion in $\mathrm{NC}-\mathrm{CAH}$ (2). Another mechanisms contributing to hyperandrogenism in $\mathrm{NC}-\mathrm{CAH}$ includes ovarian dysfunction and peripheral synthesis of androgens from steroid precursors (41). As a consequence, use of glucocorticoids around puberty in hyperandrogenic state could favor abdominal visceral adiposity, insulin resistance with concomitant metabolic derangement and further exacerbation of androgen production (45). It was recently proposed a backdoor pathway for hyperandrogenism of NC-CAH with transformation of 17-OHP and progesterone into more potent androgens such as dihydrotestosterone (46) (Supplementary Table 1).

\section{Classical $\mathrm{CAH}$}

It was observed an existence of higher rates of obesity and insulin resistance in adult patients with CAH (22). Hyperandrogenism was suggested as an intrinsic hormonal imbalance in classical CAH. Life-long glucocorticoid treatments are conferring to the increased risk for obesity and cardiovascular disease (CVD). Moreover, higher doses of glucocorticoids were associated with obesity in adults irrespectively on their family predisposition to obesity (18).

Leptin and other adipokines are elevated in almost all ages of patients with classical $\mathrm{CAH}$, and characterized with abdominal obesity, consequent changes in food consumption, insulin sensitivity, and energy homeostasis. Therefore, it seems that adipokines are involved in the pathogenesis of obesity in patients with $\mathrm{CAH}$ (47). The increase in amount of fat commenced during childhood, it is existing even in children adequately treated, and was found in young adults with CAH as well (48). However, we are lacking information on the metabolic activity of abdominal adipose tissue in CAH patients. Recently, Kim et al. (47) showed that $\mathrm{CAH}$ adolescents and young adults have increased abdominal adiposity, with a higher proportion of pro inflammatory visceral adipose tissue (VAT) than subcutaneous adipose tissue. This places $\mathrm{CAH}$ patients at even greater risk for harmful metabolic sequelae from obesity linked to CVD risk. Moreover, strong correlation was obtained between VAT and adipokines or inflammatory markers (i.e., leptin, PAI-1, and hsCRP). These findings implicated on the association of insulin resistance and metabolic syndrome in young patients with $\mathrm{CAH}$ (49). Consequently, adolescents and young adults with $\mathrm{CAH}$ express similar low-grade inflammation as obese individuals without CAH (49).

Clinical studies based on dual x-ray absorptiometry (DXA) showed that either males or females with classic CAH exhibit higher total fat mass and reduced lean body mass than controls. In respect to therapy used, a week correlation was found for cumulative glucocorticoid dose and total fat mass in females only (50). However, there was no observed differences between males and females for body composition or obesity in either classical CAH or NC-CAH $(18,40,47,51)$ (Supplementary Table 1).

\section{Impact of Therapies on the Disease Prevalence}

In respect to the therapy used, different studies analyzing patients with classical CAH showed variation in prevalence of obesity from 16.8 to $35 \%$ on hydrocortisone doses ranging from 13.3 to $15 \mathrm{mg} / \mathrm{m}^{2} /$ day while only one study reported prevalence of obesity of $60.7 \%$ on the dose of $19.5 \mathrm{mg} / \mathrm{m}^{2} /$ day (50). As meta-analyses was not performed yet, it could not be suggested a linear correlation between the prevalence of obesity and increasing doses of hydrocortisone as a frequently used therapeutic modality.

Many studies analyzing patients with $\mathrm{CAH}$ indicate an increased prevalence of insulin resistance but very few indicated an increased prevalence of diabetes including gestational diabetes. This could be partly explained with $\mathrm{CAH}$ studies analyzing patients younger than 50 as age group that is not typical for development of diabetes (4). In respect to glucocorticosteroids used, a few reports on classical CAH patients are giving opposite results with elevated insulin resistance index (HOMA-IR) in 18 and $44.4 \%$ on hydrocortisone doses of 19.5 and $11.2 \mathrm{mg} / \mathrm{m}^{2} /$ day, respectively (50).

\section{Androgen Excess and Cardiovascular Risk}

Classical $\mathrm{CAH}$ as hyperandrogenic state is characterized in women with increased cardiovascular risk (52). Either low or high testosterone levels have an increased risk for CVD independently of age, adiposity, ovarian function, and smoking (53). Traditional and non-traditional cardiovascular risk markers as well as their functional and morphological effects recognized throughout the surrogate indices, imply on the existence of increased cardiovascular risk and subclinical CVD in various types of women with androgen excess (52). Study by Falhammar et al. (54) on small number of patients analyzed cardiovascular and metabolic risk profiles in adult CAH males on lifelong glucocorticoid treatment. The authors showed that younger $\mathrm{CAH}$ males did not differ from age-matched controls while risk increased in subjects older than 30 years (54). However, we are lacking data on the frequency of established cardiovascular disease and mortality. It was shown that stroke 
is common in women with NC-CAH (odds ratio 5.8) while acute coronary syndrome is characteristic for males with classical CAH (odds ratio 9.9) (42). Hazard ratio of death was higher for females, and with $32 \%$ caused by cardiovascular diseases (55).

Higher concentrations of testosterone and DHEA in postmenopausal women are associated with the progression of atherosclerosis and development of hypertension (56). It was recently suggested an association of hyperandrogenism with the occurrence of inflammation and oxidative stress at the level of vascular endothelium, and concomitant renal reabsorption of sodium and water (56). Androgens have an adverse effects on insulin sensitivity, visceral adiposity and lipolysis, low-densitylipoprotein cholesterol (LDL-C) clearance, and high-densitylipoprotein cholesterol (HDL-C) concentrations (57). Moreover, androgen excess is deteriorating lipid profile making it more atherogenic through lower HDL-C, increased LDL-C level as a consequence of blunted LDL-receptor activity, or by enhanced lipoprotein lipase activity (57).

$\mathrm{CAH}$ is characterized by an existence of cardiovascular risk factors including dyslipidemia, obesity and insulin resistance, as well as cardiovascular outcomes as hypertension (58). There is a similarity in respect to the presence of cardiovascular risk factors in $\mathrm{CAH}$ patients and PCOS patients. Glucocorticoid used in high doses for the androgen suppression could induce Cushing syndrome characteristics with further aggravation of existing cardiovascular risk factors (59). Some data in children's populations showed decreased HDL-C in $\sim 10 \%$ of both classic CAH and NC-CAH subjects (18). In another study, an association of androgen concentrations with dyslipidemia, obesity, and IR was shown in CAH patients (58) as well as elevated triglyceride concentrations confirmed in children with classical CAH on prednisone therapy (60). Moreover, prepubertal children with classical $\mathrm{CAH}$ could have elevated leptin and insulin levels constituting a group with increased life-long cardiovascular risk (61).

Hypertension is frequent finding in patients with classical CAH. It could be a consequence of the disease or the effect of therapy. Moreover, hypertension is considered the main cause of cardiovascular morbidity in young patients with CAH (62). In respect to the activity of the disease, elevated blood pressure was more likely diagnosed all patients with classical CAH than in NC$\mathrm{CAH}$ ones, and associated with children of younger age and adult male gender, respectively (18). Moreover, deranged systolic blood pressure in children with classical CAH was characterized with higher daytime values and the absence of the nocturnal descent (63). Monitoring of blood pressure in children is of importance. Namely, it was observed an increased hypertension rate in young patients with classical CAH on fludrocortisone therapy (64). Available studies on CAH patients of different age showed similar prevalence of hypertension between males and females with $\mathrm{CAH}$ $(18,40,63)$ with few exceptions showing more deteriorated BP in younger females likely to be related to androgen excess (50).

Carotid intima-media thickness (CIMT) is used as surrogate marker of arterial damage. It was shown that CIMT was increased in $\mathrm{CAH}$ patients including different age groups and independently of androgen levels, insulin levels or glucocorticoid treatment (65). Moreover, when comparing adolescents with classical $\mathrm{CAH}$ and $\mathrm{NC}-\mathrm{CAH}$, even those with $\mathrm{NC}-\mathrm{CAH}$ may be at higher risk of having increased CIMT, possibly related to intermittent iatrogenic hypercortisolism and secondary insulin resistance (66). In respect to gender differences, there was no association between CIMT and androstenedione and $17 \mathrm{OH}$ progesterone in exposed females with classical CAH (51) (Supplementary Table 1).

\section{Bone Mineral Density and Risk for Osteoporosis}

Adult patients with classical $\mathrm{CAH}$ are shorter than average individuals in the general population by $\sim 10 \mathrm{~cm}$ (17). This is caused by the parallel effects of earlier exposure to androgens causing accelerated growth rate in childhood and premature epiphyseal closure in the long bones, and suppressive effects of excessive GCS doses on the secretion of growth hormone on the other.

The age and duration-related data on the assessment of bone mineral density (BMD) in patients with $\mathrm{CAH}$ are varying. While some authors showed lower BMD in adults with classical $\mathrm{CAH}$ and $\mathrm{NC}-\mathrm{CAH}$ (18) others showed differences in BMD in relation only to glucocorticoid use (67). Curiously, while GCS therapy in children did not show a decrease in BMD, significantly lower BMD was demonstrated in adult patients with $\mathrm{CAH}$ on GCS treatment, and specially in those having saltwasting CAH managed with highest doses of GCS $(68,69)$. In respect to the drug used, lower BMD values are found in patients managed with longer-acting GCS compared to those managed with hydrocortisone (70). An additional factor influencing decrease in BMD could be the reduced levels of DHEA and DHEAS that was shown in post-menopausal women treated with long-acting GCS (68).

Apart from the assessment of height and BMD using dual energy X-ray absorptiometry, there is not an established role for the bone turnover biochemical markers in patients with CAH (69).

Use of glucocorticoids could result in long-term complications including osteoporosis and fractures (4). In respect to the CAH variant, while some authors reported normal or even better BMD in different age-groups of patients with $\mathrm{NC}-\mathrm{CAH}$ in comparison to classical $\mathrm{CAH}(71,72)$, other authors found similar frequency of osteoporosis in NCAH in comparison to classical CAH (18).

Osteoporosis could be expected in adults with classical CAH on chronic glucocorticoid therapy. GCS therapy is influencing the activity of osteoblasts with consequent decreased in BMD (67). In line with this is low activity of the markers of bone formation such as osteocalcin, in adults with $\mathrm{CAH}$ (73). Apart from the more pronounced decrease in BMD after the age of 30 , an increased rate of osteoporotic fractures was shown in women with classic CAH treated with GCS (71). Moreover, males older than 30 years had lower BMD in all measured sites similarly to women of the same age $(67,71)$. However, in spite of lower BMD and osteocalcin concentrations in males on prednisolone therapy in comparison to the ones hydrocortisone treatment, they did not have higher frequency of fractures (67). 
Taking into consideration all the aspects of GCS treatment on $\mathrm{BMD}$, and in spite of decreased bone turnover markers, most patients with $\mathrm{CAH}$ have normal BMD. Preservation of bone integrity over GCS treatment could be explained with the commonly increased body mass index, which is protective to bones, as well as with the anabolic effects of androgens in both males and females (73). However, the most likely explanation for the preserved BMD could rely in the positive net effect of the GCS type and dose adjustment during patient's follow-up (Supplementary Table 1).

\section{CONCLUSION}

Patients with NC-CAH are prone to develop metabolic consequences. Those patients are with higher rates of obesity and insulin resistance, as well as with increased rates of metabolic sequelae and cardiovascular disease during an adult period in both males and females. These patients could be at higher risk of having increased arterial intima-media thickness, possibly related to intermittent iatrogenic hypercortisolism and secondary insulin resistance. Decreased BMD and osteoporosis is not a constant

\section{REFERENCES}

1. Bidet M, Bellanne-Chantelot C, Galand-Portier MB, Tardy V, Billaud L, Laborde K, et al. Clinical and molecular characterization of a cohort of 161 unrelated women with nonclassical congenital adrenal hyperplasia due to 21hydroxylase deficiency and 330 family members. J Clin Endocrinol Metab. (2009) 94:1570-8. doi: 10.1210/jc.2008-1582

2. Witchel SF, Azziz R. Nonclassic congenital adrenal hyperplasia. Int J Pediatr Endocrinol. (2010) 2010:625105. doi: 10.1186/1687-9856-2010-625105

3. Marino R, Ramirez P, Galeano J, Perez Garrido N, Rocco C, Ciaccio M, et al. Steroid 21-hydroxylase gene mutational spectrum in 454 Argentinean patients: genotype-phenotype correlation in a large cohort of patients with congenital adrenal hyperplasia. Clin Endocrinol. (2011) 75:42735. doi: 10.1111/j.1365-2265.2011.04123.x

4. Nordenstrom A, Falhammar H. Management of endocrine disease: diagnosis and management of the patient with non-classic CAH due to 21-hydroxylase deficiency. Eur J Endocrinol. (2019) 180:R127-45. doi: 10.1530/EJE-18-0712

5. Livadas S, Dracopoulou M, Dastamani A, Sertedaki A, Maniati-Christidi M, Magiakou AM, et al. The spectrum of clinical, hormonal and molecular findings in 280 individuals with nonclassical congenital adrenal hyperplasia caused by mutations of the CYP21A2 gene. Clin Endocrinol. (2015) 82:5439. doi: $10.1111 / \mathrm{cen} .12543$

6. White PC, Speiser PW. Congenital adrenal hyperplasia due to 21-hydroxylase deficiency. Endocr Rev. (2000) 21:245-91. doi: 10.1210/er.21.3.245

7. Nordenstrom A, Ahmed S, Jones J, Coleman M, Price DA, Clayton PE, et al. Female preponderance in congenital adrenal hyperplasia due to CYP21 deficiency in England: implications for neonatal screening. Horm Res. (2005) 63:22-8. doi: 10.1159/000082896

8. van der Kamp HJ, Wit JM. Neonatal screening for congenital adrenal hyperplasia. Eur J Endocrinol. (2004) 151(Suppl. 3):U715. doi: 10.1530/eje.0.151u071

9. Speiser PW, Dupont B, Rubinstein P, Piazza A, Kastelan A, New MI. High frequency of nonclassical steroid 21-hydroxylase deficiency. Am J Hum Genet. (1985) 37:650-67.

10. Kuttenn F, Couillin P, Girard F, Billaud L, Vincens M, Boucekkine C, et al. Late-onset adrenal hyperplasia in hirsutism. N Engl J Med. (1985) 313:22431. doi: 10.1056/NEJM198507253130404

11. Pall M, Azziz R, Beires J, Pignatelli D. The phenotype of hirsute women: a comparison of polycystic ovary syndrome and 21-hydroxylasedeficient nonclassic adrenal hyperplasia. Fertil Steril. (2010) 94:6849. doi: 10.1016/j.fertnstert.2009.06.025 finding in these patients and could depend on the sex, and type or dose of glucocorticosteroids applied.

\section{AUTHOR CONTRIBUTIONS}

The present work was designed by DM, VZ, JB-M, GM, and DP. The initial manuscript draft was prepared by DM and subsequently revised by VZ, J-BM, GM, and DP. All the authors approved the final submitted version.

\section{FUNDING}

This study was funded by the Serbian Ministry of Education, Science and Technological Development (grant numbers 175032 and 41009).

\section{SUPPLEMENTARY MATERIAL}

The Supplementary Material for this article can be found online at: https://www.frontiersin.org/articles/10.3389/fendo. 2019.00681/full\#supplementary-material

12. Oberfield SE, Sopher AB, Gerken AT. Approach to the girl with early onset of pubic hair. J Clin Endocrinol Metab. (2011) 96:161022. doi: 10.1210/jc.2011-0225

13. Speiser PW, Azziz R, Baskin LS, Ghizzoni L, Hensle TW, Merke DP, et al. Congenital adrenal hyperplasia due to steroid 21-hydroxylase deficiency: an Endocrine Society clinical practice guideline. J Clin Endocrinol Metab. (2010) 95:4133-60. doi: 10.1210/jc.2009-2631

14. Bonfig W, Schmidt H, Schwarz HP. Growth patterns in the first three years of life in children with classical congenital adrenal hyperplasia diagnosed by newborn screening and treated with low doses of hydrocortisone. Horm Res Paediatr. (2011) 75:32-7. doi: 10.1159/000316973

15. Bonfig W, Schwarz HP. Growth pattern of untreated boys with simple virilizing congenital adrenal hyperplasia indicates relative androgen insensitivity during the first six months of life. Horm Res Paediatr. (2011) 75:264-8. doi: 10.1159/000322580

16. Bonfig W. Growth and development in children with classic congenital adrenal hyperplasia. Curr Opin Endocrinol Diabetes Obes. (2017) 24:3942. doi: 10.1097/MED.0000000000000308

17. Eugster EA, Dimeglio LA, Wright JC, Freidenberg GR, Seshadri R, Pescovitz $\mathrm{OH}$. Height outcome in congenital adrenal hyperplasia caused by 21-hydroxylase deficiency: a meta-analysis. J Pediatr. (2001) 138:2632. doi: $10.1067 / \mathrm{mpd} .2001 .110527$

18. Finkielstain GP, Kim MS, Sinaii N, Nishitani M, Van Ryzin C, Hill SC, et al. Clinical characteristics of a cohort of 244 patients with congenital adrenal hyperplasia. J Clin Endocrinol Metab. (2012) 97:442938. doi: 10.1210/jc.2012-2102

19. Bonfig W, Pozza SB, Schmidt H, Pagel P, Knorr D, Schwarz HP. Hydrocortisone dosing during puberty in patients with classical congenital adrenal hyperplasia: an evidence-based recommendation. J Clin Endocrinol Metab. (2009) 94:3882-8. doi: 10.1210/jc.2009-0942

20. Volkl TM, Ohl L, Rauh M, Schofl C, Dorr HG. Adrenarche and puberty in children with classic congenital adrenal hyperplasia due to 21-hydroxylase deficiency. Horm Res Paediatr. (2011) 76:400-10. doi: 10.1159/000333696

21. Dacou-Voutetakis C, Karidis N. Congenital adrenal hyperplasia complicated by central precocious puberty: treatment with LHRH-agonist analogue. Ann N Y Acad Sci. (1993) 687:250-4. doi: 10.1111/j.1749-6632.1993.tb43873.x

22. Krone N, Rose IT, Willis DS, Hodson J, Wild SH, Doherty EJ, et al. Genotype-phenotype correlation in 153 adult patients with congenital adrenal hyperplasia due to 21-hydroxylase deficiency: analysis of the United Kingdom Congenital adrenal Hyperplasia Adult Study Executive (CaHASE) cohort. $J$ Clin Endocrinol Metab. (2013) 98:E346-54. doi: 10.1210/jc.2012-3343 
23. Idkowiak J, Lavery GG, Dhir V, Barrett TG, Stewart PM, Krone N, et al. Premature adrenarche: novel lessons from early onset androgen excess. Eur J Endocrinol. (2011) 165:189-207. doi: 10.1530/EJE-11-0223

24. Voutilainen R, Jaaskelainen J. Premature adrenarche: etiology, clinical findings, and consequences. J Steroid Biochem Mol Biol. (2015) 145:22636. doi: 10.1016/j.jsbmb.2014.06.004

25. Reisch N, Hogler W, Parajes S, Rose IT, Dhir V, Gotzinger J, et al. A diagnosis not to be missed: nonclassic steroid 11beta-hydroxylase deficiency presenting with premature adrenarche and hirsutism. J Clin Endocrinol Metab. (2013) 98:E1620-5. doi: 10.1210/jc.2013-1306

26. Utriainen P, Voutilainen R, Jaaskelainen J. Continuum of phenotypes and sympathoadrenal function in premature adrenarche. Eur J Endocrinol. (2009) 160:657-65. doi: 10.1530/EJE-08-0367

27. Utriainen P, Laakso S, Liimatta J, Jaaskelainen J, Voutilainen R. Premature adrenarche-a common condition with variable presentation. Horm Res Paediatr. (2015) 83:221-31. doi: 10.1159/000369458

28. Pignatelli D. Non-classic adrenal hyperplasia due to the deficiency of 21hydroxylase and its relation to polycystic ovarian syndrome. Front Horm Res. (2013) 40:158-70. doi: 10.1159/000342179

29. Skordis N, Shammas C, Efstathiou E, Kaffe K, Neocleous V, Phylactou LA. Endocrine profile and phenotype-genotype correlation in unrelated patients with non-classical congenital adrenal hyperplasia. Clin Biochem. (2011) 44:959-63. doi: 10.1016/j.clinbiochem.2011.05.013

30. Conway G, Dewailly D, Diamanti-Kandarakis E, Escobar-Morreale HF, Franks S, Gambineri A, et al. The polycystic ovary syndrome: a position statement from the European Society of Endocrinology. Eur J Endocrinol. (2014) 171:P1-29. doi: 10.1530/EJE-14-0253

31. Honour JW. 17-Hydroxyprogesterone in children, adolescents and adults. Ann Clin Biochem. (2014) 51:424-40. doi: 10.1177/0004563214529748

32. Rosenfield RL, Mortensen M, Wroblewski K, Littlejohn E, Ehrmann DA. Determination of the source of androgen excess in functionally atypical polycystic ovary syndrome by a short dexamethasone androgensuppression test and a low-dose ACTH test. Hum Reprod. (2011) 26:313846. doi: 10.1093/humrep/der291

33. Holmes-Walker DJ, Conway GS, Honour JW, Rumsby G, Jacobs HS. Menstrual disturbance and hypersecretion of progesterone in women with congenital adrenal hyperplasia due to 21-hydroxylase deficiency. Clin Endocrinol. (1995) 43:291-6. doi: 10.1111/j.1365-2265.1995.tb02034.x

34. Auchus RJ, Arlt W. Approach to the patient: the adult with congenital adrenal hyperplasia. J Clin Endocrinol Metab. (2013) 98:2645-55. doi: 10.1210/jc.2013-1440

35. Charmandari E, Brook CG, Hindmarsh PC. Classic congenital adrenal hyperplasia and puberty. Eur J Endocrinol. (2004) 151(Suppl. 3):U7782. doi: 10.1530/eje.0.151u077

36. Deslauriers JR, Lenz AM, Root AW, Diamond FB, Bercu BB. Gender related differences in glucocorticoid therapy and growth outcomes among pubertal children with 21-hydroxylase deficiency congenital adrenal hyperplasia (CAH). J Pediatr Endocrinol Metab. (2012) 25:977-81. doi: 10.1515/jpem-2012-0125

37. Hindmarsh PC, Charmandari E. Variation in absorption and half-life of hydrocortisone influence plasma cortisol concentrations. Clin Endocrinol. (2015) 82:557-61. doi: 10.1111/cen.12653

38. Porter J, Blair J, Ross RJ. Is physiological glucocorticoid replacement important in children? Arch Dis Child. (2017) 102:199-205. doi: 10.1136/archdischild-2015-309538

39. Saygili F, Oge A, Yilmaz C. Hyperinsulinemia and insulin insensitivity in women with nonclassical congenital adrenal hyperplasia due to 21-hydroxylase deficiency: the relationship between serum leptin levels and chronic hyperinsulinemia. Horm Res. (2005) 63:270-4. doi: 10.1159/000086363

40. Subbarayan A, Dattani MT, Peters CJ, Hindmarsh PC. Cardiovascular risk factors in children and adolescents with congenital adrenal hyperplasia due to 21-hydroxylase deficiency. Clin Endocrinol. (2014) 80:471-7. doi: 10.1111/cen.12265

41. Carmina E, Dewailly D, Escobar-Morreale HF, Kelestimur F, Moran C, Oberfield S, et al. Non-classic congenital adrenal hyperplasia due to 21-hydroxylase deficiency revisited: an update with a special focus on adolescent and adult women. Hum Reprod Update. (2017) 23:58099. doi: 10.1093/humupd/dmx014

42. Falhammar H, Frisen L, Hirschberg AL, Norrby C, Almqvist C, Nordenskjold A, et al. Increased cardiovascular and metabolic morbidity in patients with 21 hydroxylase deficiency: a Swedish Population-Based National Cohort Study. J Clin Endocrinol Metab. (2015) 100:3520-8. doi: 10.1210/JC.2015-2093

43. Azziz R, Dewailly D, Owerbach D. Clinical review 56: nonclassic adrenal hyperplasia: current concepts. J Clin Endocrinol Metab. (1994) 78:8105. doi: 10.1210/jcem.78.4.8157702

44. Carmina E. Pathogenesis and treatment of hirsutism in lateonset congenital adrenal hyperplasia. Reprod Med Rev. (1995) 4:179-87. doi: 10.1017/S0962279900000569

45. Kim MS, Merke DP. Cardiovascular disease risk in adult women with congenital adrenal hyperplasia due to 21-hydroxylase deficiency. Semin Reprod Med. (2009) 27:316-21. doi: 10.1055/s-0029-1225259

46. Kamrath C, Hochberg Z, Hartmann MF, Remer T, Wudy SA. Increased activation of the alternative "backdoor" pathway in patients with 21hydroxylase deficiency: evidence from urinary steroid hormone analysis. $J$ Clin Endocrinol Metab. (2012) 97:E367-75. doi: 10.1210/jc.2011-1997

47. Kim MS, Ryabets-Lienhard A, Dao-Tran A, Mittelman SD, Gilsanz $\mathrm{V}$, Schrager SM, et al. Increased abdominal adiposity in adolescents and young adults with classical congenital adrenal hyperplasia due to 21-hydroxylase deficiency. J Clin Endocrinol Metab. (2015) 100:E11539. doi: 10.1210/jc.2014-4033

48. Stikkelbroeck NM, Oyen WJ, van der Wilt GJ, Hermus AR, Otten BJ. Normal bone mineral density and lean body mass, but increased fat mass, in young adult patients with congenital adrenal hyperplasia. J Clin Endocrinol Metab. (2003) 88:1036-42. doi: 10.1210/jc.2002-021074

49. Cali AM, Caprio S. Obesity in children and adolescents. J Clin Endocrinol Metab. (2008) 93:S31-6. doi: 10.1210/jc.2008-1363

50. Improda N, Barbieri F, Ciccarelli GP, Capalbo D, Salerno M. Cardiovascular health in children and adolescents with congenital adrenal hyperplasia due to 21-hydroxilase deficiency. Front Endocrinol. (2019) 10:212. doi: 10.3389/fendo.2019.00212

51. Abd El Dayem SM, Anwar GM, Salama H, Kamel AF, Emara N. Bone mineral density, bone turnover markers, lean mass, and fat mass in Egyptian children with congenital adrenal hyperplasia. Arch Med Sci. (2010) 6:10410. doi: 10.5114/aoms.2010.13516

52. Macut D, Antic IB, Bjekic-Macut J. Cardiovascular risk factors and events in women with androgen excess. J Endocrinol Invest. (2015) 38:295301. doi: 10.1007/s40618-014-0215-1

53. Laughlin GA, Goodell V, Barrett-Connor E. Extremes of endogenous testosterone are associated with increased risk of incident coronary events in older women. J Clin Endocrinol Metab. (2010) 95:740-7. doi: 10.1210/jc.2009-1693

54. Falhammar H, Filipsson Nystrom H, Wedell A, Thoren M. Cardiovascular risk, metabolic profile, and body composition in adult males with congenital adrenal hyperplasia due to 21-hydroxylase deficiency. Eur J Endocrinol. (2011) 164:285-93. doi: 10.1530/EJE-10-0877

55. Bachelot A, Grouthier V, Courtillot C, Dulon J, Touraine P. Management of endocrine disease: congenital adrenal hyperplasia due to 21-hydroxylase deficiency: update on the management of adult patients and prenatal treatment. Eur J Endocrinol. (2017) 176:R167-81. doi: 10.1530/EJE-16-0888

56. Wang L, Szklo M, Folsom AR, Cook NR, Gapstur SM, Ouyang P. Endogenous sex hormones, blood pressure change, and risk of hypertension in postmenopausal women: the Multi-Ethnic Study of Atherosclerosis. Atherosclerosis. (2012) 224:228-34. doi: 10.1016/j.atherosclerosis.2012.07.005

57. Diamanti-Kandarakis E, Papavassiliou AG, Kandarakis SA, Chrousos GP. Pathophysiology and types of dyslipidemia in PCOS. Trends Endocrinol Metab. (2007) 18:280-5. doi: 10.1016/j.tem.2007.07.004

58. Arlt W, Willis DS, Wild SH, Krone N, Doherty EJ, Hahner S, et al. Health status of adults with congenital adrenal hyperplasia: a cohort study of 203 patients. J Clin Endocrinol Metab. (2010) 95:5110-21. doi: 10.1210/jc.2010-0917

59. Mancini T, Kola B, Mantero F, Boscaro M, Arnaldi G. High cardiovascular risk in patients with Cushing's syndrome according to $1999 \mathrm{WHO} / \mathrm{ISH}$ guidelines. Clin Endocrinol. (2004) 61:768-77. doi: 10.1111/j.1365-2265.2004.02168.x 
60. Botero D, Arango A, Danon M, Lifshitz F. Lipid profile in congenital adrenal hyperplasia. Metabolism. (2000) 49:790-3. doi: 10.1053/meta.2000.6261

61. Charmandari E, Weise M, Bornstein SR, Eisenhofer G, Keil MF, Chrousos GP, et al. Children with classic congenital adrenal hyperplasia have elevated serum leptin concentrations and insulin resistance: potential clinical implications. $J$ Clin Endocrinol Metab. (2002) 87:2114-20. doi: 10.1210/jcem.87.5.8456

62. Volkl TM, Simm D, Dotsch J, Rascher W, Dorr HG. Altered 24-hour blood pressure profiles in children and adolescents with classical congenital adrenal hyperplasia due to 21-hydroxylase deficiency. J Clin Endocrinol Metab. (2006) 91:4888-95. doi: 10.1210/jc.2006-1069

63. Roche EF, Charmandari E, Dattani MT, Hindmarsh PC. Blood pressure in children and adolescents with congenital adrenal hyperplasia (21hydroxylase deficiency): a preliminary report. Clin Endocrinol. (2003) 58:58996. doi: 10.1046/j.1365-2265.2003.01757.x

64. Maccabee-Ryaboy N, Thomas W, Kyllo J, Lteif A, Petryk A, Gonzalez-Bolanos MT, et al. Hypertension in children with congenital adrenal hyperplasia. Clin Endocrinol. (2016) 85:528-34. doi: 10.1111/cen.13086

65. Harrington J, Pena AS, Gent R, Hirte C, Couper J. Adolescents with congenital adrenal hyperplasia because of 21-hydroxylase deficiency have vascular dysfunction. Clin Endocrinol. (2012) 76:837-42. doi: 10.1111/j.1365-2265.2011.04309.x

66. Wasniewska M, Balsamo A, Valenzise M, Manganaro A, Faggioli G, Bombaci $S$, et al. Increased large artery intima media thickness in adolescents with either classical or non-classical congenital adrenal hyperplasia. J Endocrinol Invest. (2013) 36:12-5. doi: 10.1007/BF03346751

67. Falhammar H, Filipsson Nystrom H, Wedell A, Brismar K, Thoren M. Bone mineral density, bone markers, and fractures in adult males with congenital adrenal hyperplasia. Eur J Endocrinol. (2013) 168:33141. doi: 10.1530/EJE-12-0865

68. King JA, Wisniewski AB, Bankowski BJ, Carson KA, Zacur HA, Migeon CJ. Long-term corticosteroid replacement and bone mineral density in adult women with classical congenital adrenal hyperplasia. J Clin Endocrinol Metab. (2006) 91:865-9. doi: 10.1210/jc.2005-0745
69. Ambroziak U, Bednarczuk T, Ginalska-Malinowska M, Malunowicz EM, Grzechocinska B, Kaminski P, et al. Congenital adrenal hyperplasia due to 21-hydroxylase deficiency - management in adults. Endokrynol Pol. (2010) 61:142-55.

70. Jaaskelainen J, Voutilainen R. Bone mineral density in relation to glucocorticoid substitution therapy in adult patients with 21-hydroxylase deficiency. Clin Endocrinol. (1996) 45:707-13. doi: $\quad 10.1046 /$ j.1365-2265.1996.862

0871.x

71. Falhammar H, Filipsson H, Holmdahl G, Janson PO, Nordenskjold A, Hagenfeldt $\mathrm{K}$, et al. Fractures and bone mineral density in adult women with 21-hydroxylase deficiency. J Clin Endocrinol Metab. (2007) 92:46439. doi: 10.1210/jc.2007-0744

72. Paganini C, Radetti G, Livieri C, Braga V, Migliavacca D, Adami S. Height, bone mineral density and bone markers in congenital adrenal hyperplasia. Horm Res. (2000) 54:164-8. doi: 10.1159/00005 3253

73. Ogilvie CM, Rumsby G, Kurzawinski T, Conway GS. Outcome of bilateral adrenalectomy in congenital adrenal hyperplasia: one unit's experience. Eur J Endocrinol. (2006) 154:405-8. doi: 10.1530/eje.1. 02096

Conflict of Interest: The authors declare that the research was conducted in the absence of any commercial or financial relationships that could be construed as a potential conflict of interest.

Copyright (C) 2019 Macut, Zdravković, Bjekić-Macut, Mastorakos and Pignatelli. This is an open-access article distributed under the terms of the Creative Commons Attribution License (CC BY). The use, distribution or reproduction in other forums is permitted, provided the original author(s) and the copyright owner(s) are credited and that the original publication in this journal is cited, in accordance with accepted academic practice. No use, distribution or reproduction is permitted which does not comply with these terms. 